\title{
Crónica sobre el Webinar Coronavirus y Animales
}

\author{
Iván Fructuoso González \\ Letrado de la Administración de Justicia \\ Director del Servicio Común y Decanato de Sabadell
}

Cita recomendada. FRUCTUOSO GONZÁLEZ, I., Crónica sobre el Webinar Coronavirus y Animales, dA. Derecho Animal (Forum of Animal Law Studies) 11/4 (2020). - DOI https://doi.org/10.5565/rev/da.541

\section{Resumen}

A lo largo de más de tres semanas, entre el 22 de junio y el 15 de julio de este año, se celebró el Webinar Coronavirus y Animales, organizado por el ICALP, dedicado al análisis del impacto del Covid 19 en los animales y a la relación humano-animal en los tiempos de pandemia.

Palabras clave: animales; Derecho Animal; ICALP; UAB; Webinar; COVID-19.

\section{Abstract - Chronicle on Coronavirus and Animals Webinar}

Across three weeks, between June 22nd and July 15th this year, the Coronavirus and Animals Webinar took place, organised by ICALP and dedicated towards analysing the impact of Covid 19 on animals and the human-animal relationship in times of pandemic.

Keywords: animals; Animal Law; ICALP; UAB; Webinar; COVID-19.

Coronavirus y Animales se organizó a través de una serie de conferencias impartidas por prestigiosas personalidades del mundo del Derecho y la Ciencia, combinadas con sesiones "en vivo" donde intervenían tanto conferenciantes como asistentes, que formulaban preguntas y exponían sus dudas e ideas, creándose con ello un ambiente constructivo y un valioso feedback entre todos los intervinientes. De esa forma, en algunas ocasiones pudimos disfrutar doblemente de las exposiciones de determinados conferenciantes, que nos remitieron sus brillantes exposiciones pero que a su vez intervinieron en las sesiones "en vivo".

La apertura de las sesiones tuvo lugar el 22 de junio y corrió a cargo de la Rectora de la Universitat Autònoma de Barcelona, la Dra. Margarita Arboix, a la que siguieron unas palabras de la Dra. Marita Giménez-Candela, directora del ICALP, y del Dr. Martí Pomarola, Catedrático del Departamento de Medicina y Cirugía Animales de la UAB.

A continuación, la Dra. Anne Peters, Directora del Max-Planck-Institut für Ausländisches öffentliches Recht und Völkerrecht de Heidelberg (Alemania), ofreció una interesante visión de las consecuencias negativas para el ser humano del uso y abuso del resto de especies animales, llegando a la conclusión de que 
el "paradigma de salud única", tal como lo propugna la Organización Internacional de Epizootias (OIE), debe complementarse con un paradigma de "bienestar único".

El 23 de junio pudimos acceder a tres nuevas conferencias. En primer lugar, el Dr. Pomarola realizó una brillante charla sobre la incidencia de las enfermedades animales en humanos y viceversa, desde una perspectiva histórica. Su exposición, titulada Enfermedad animal, zoonosis y One health: lo que hemos aprendido los veterinarios a lo largo de la historia, concluía con la formulación y desarrollo del concepto One Health - salud única -, y la necesidad de una cooperación interdisciplinar para enfrentarnos con solvencia a situaciones pandémicas como la actual.

Por su parte, el Dr. Albert Lloret, veterinario del Hospital Clinic Veterinari-UAB, ofreció una disquisición acerca del impacto del Covid 19 en gatos, alertándonos sobre la necesidad de mantener con los gatos las mismas medidas de protección e higiene que con los seres humanos.

Por último, el Dr. Jaume Fatjó, de la Cátedra Affinity, analizó la incidencia del Coronavirus en las relaciones entre seres humanos y sus animales de compañía.

El 24 de junio contamos con tres nuevas sesiones. En primer lugar, el Dr. Riccardo Cardilli, de la Facoltà di Giurisprudenzia. Università di Tor Vergata de Roma (Italia) explicó el concepto y distinción entre los conceptos de pandemia y epidemia, así como un análisis de las pandemias a lo largo de la Historia, con especial atención a la plaga antonina en la Roma del siglo II dC y las epidemias en Atenas. Asimismo, comparó las perspectivas de la Ley actual y el Derecho Romano ante situaciones extraordinarias como las pandemias. Por último, centró su atención en la teoría de Ausnahmezustand, de Carl Schmitt.

Por su parte, el Dr. Alberto Varona, profesor de la Escuela Judicial de Barcelona, explicó el significado y funcionamiento del estado de alarma y examinó el delito leve de maltrato animal del art. 337 bis del Código Penal español, insistiendo en que el principio de intervención mínima y de última ratio del Derecho Penal es un mandato al poder legislativo y no al judicial.

La tercera conferencia corrió a cargo de la propia directora del ICALP, Marita Giménez-Candela, que formuló, bajo el título Tenencia responsable de animales de compañía. Perspectiva global durante la pandemia, una reconsideración sobre la tenencia responsable los animales de compañía en una situación de alarma sanitaria, a raíz del Real Decreto 463/2020 de 14 de marzo, que declaró el estado de alarma en España debido a la situación de crisis sanitaria provocada por el Coronavirus, y que introdujo algunas importantes medidas respecto al cuidado de los animales de compañía. Entre ellas, la autorización de salir a la calle para pasear a los perros y llevarlos al veterinario, así como la autorización de permanecer abiertos los supermercados y tiendas de nutrición para animales, para facilitar la adquisición de productos de alimentación para los mismos.

La sesión en vivo del 25 de junio de 2020 comenzó con una exposición de Loïs Lelanchon, responsable de programas en International Fund for Animal Welfare (IFAW). Bajo el título Reducción del riesgo de eventos de propagación zoonótica de animales silvestres, el Sr. Lelanchon llamó la atención sobre el impacto de la actividad destructiva de seres humanos sobre el medioambiente, que deriva en un aumento de la tendencia contactos y conflictos entre la especie humana y la fauna silvestre la cual está desembocando en transmisiones de agentes zoonóticos. Para reducir este tipo de transmisiones, el Sr. Lelanchon propone que la fauna silvestre se mantenga intacta en sus hábitats naturales, minimizando la interacción con los seres humanos y restringiendo su comercio y su uso, prohibiendo el comercio de animales silvestres, y aumentando los esfuerzos para combatir los crímenes contra la fauna silvestre.

La segunda conferencia del día corrió a cargo de Carles-Joan Lorente Rivera, profesor asociado del Departamento de Derecho público y Ciencias Histórico-Jurídicas en la UAB, con su intervención titulada COVID-19. Animales en las Administraciones públicas: ¿Protección animal o protección ciudadana? En ella abordó la convivencia entre humanos y animales, desde la óptica de la Administración Pública, en concreto el Ayuntamiento de Sabadell.

Por último, intervino la Dra. Inês de Sousa Real, jurista, miembro de la Asamblea de la República Portuguesa, quien analizó las políticas públicas de protección animal promovidas en Portugal en tiempos de pandemia. En su intervención, recalcó que la crisis del Covid 19 presenta repercusiones globales, afectando a diferentes dimensiones, como la salud, la economía, los derechos laborales, pero también los animales y el medio ambiente.

La declaración del Estado de Emergencia en Portugal conllevó una restricción de los derechos y libertades de los ciudadanos, en el que se presenta como esencial garantizar que los animales, especialmente los de compañía, domesticados o errantes, sean protegidos.

El 29 de junio se añadió al ya profuso catálogo el speech de V. Alex Bruce, de la Australian National University de Canberra (Australia), acerca de las revelaciones inesperadas de los Zoos sobre las relaciones entre humanos y animales en un mundo de COVID-19, alertando sobre el estrés que sufren los animales sometidos a cautiverio en zoológicos, debido a la intrusión diaria de cientos de visitantes humanos inquisitivos 
y ruidosos. Sin embargo, el cierre por la pandemia de la mayoría de los zoológicos del mundo ha producido en determinados animales signos de soledad y letargo como resultado de la ausencia de contacto humano diario.

Al día siguiente, pudimos acceder al trabajo de la Sra. Silvia Zanini, de la Università di Ca Foscari, en Venecia (Italia) que, a través de una exposición titulada Covid-19 y la relación hombre-naturaleza: el equilibrio violado. El principio de precaución ante la complejidad de la pandemia, puso el foco en la relación directa existente entre la acción humana sobre la naturaleza y la propagación de enfermedades como el Covid 19, desempeñando la alteración del equilibrio en la relación entre el hombre y los entornos naturales un papel crucial en la propagación del virus. Asimismo, expuso la existencia de estudios que están hallando un vínculo directo entre la propagación del virus y el cambio climático, fruto de la negativa relación de interdependencia entre el hombre, los animales y el medio ambiente en general.

Ese mismo día, el Dr. Joan Amenós, profesor de Derecho Administrativo de la UAB, ofreció una disertación acerca de la situación de los espacios naturales y las zonas verdes tras la pandemia. El profesor Amenós defendió la huida del estado de "frivolización pueril" y "subasta ideológica" en que se hallaba la salvaguarda de la naturaleza, para lo que propuso un retorno a la Ciencia y un alejamiento del "twitter y la pancarta".

Las sesiones en vivo del 1 de julio de 2020 comenzaron con la intervención de la periodista Kristin Suleng, que presentó una conferencia titulada Life is the center. The challenge of ecocentric media construction and dissemination of animal welfare in times of health crisis. Local experiences, centrándose en la contribución de los medios de comunicación en la protección del mediomabiente y del bienestar animal, analizando el caso concreto de Samarucdigital, que denuncia el declive del ecosistema valenciano. En definitiva, Kristin Suleng concluye que los medios de comunicación deben actuar de forma equilibrada, sin caer en el catastrofismo, pero sin resultar superficiales.

A continuación, la Dra. Ma Filipa Castanheira (Fish Ethology and Welfare group, CCMAR. Portugal), en su conferencia Garantizar el bienestar de las especies acuicolas durante una situación de pandemia: la importancia de los esquemas de certificación y las medidas adaptadas, elaborada con la Dra. Ana Roque (del IRTA de Sant Carles de la Ràpita) puso el acento sobre la necesidad de practicar una acuicultura responsable, que garantice óptimas condiciones y adecuada calidad de vida para los animales criados. Para lograr tal objetivo, proponen la implementación de criterios y estándares de bienestar de los peces para la industria y nuevos esquemas de certificaciones.

Las sesiones se reanudaron el 2 de julio con la intervención del Dr.Philip Limbery, Global CEO de Compassion in World Farming (Reino Unido) y una conferencia titulada Coronavirus: eestá la próxima pandemia en nuestro plato?, en la que expuso la idea de que la forma en que ahora producimos tanta comida en todo el mundo pueda estar preparando la próxima pandemia. Para el Dr. Limbery, mantener a los animales enjaulados, amontonados y confinados condiciona el caldo de cultivo ideal para nuevas y más mortales cepas de virus.

El Dr. Jordi Serratosa, profesor asociado de Veterinaria y legislación alimenticia en la Universitat Autònoma de Barcelona, habló de las tendencias futuras de los consumidores e interesados en el terreno del bienestar animal y su impacto en los alimentos de origen animal y la posibilidad de introducir valores éticos en la producción animal.

Por su parte, la Dra. Ángela Vivanco, Ministra de la Corte Suprema de Chile, habló acerca de la situación de los animales ante la situación de alarma sanitaria por Covid-19, revisando qué sucede, jurídicamente hablando, con el trato a los animales, tanto domésticos como de granja y especies nativas.

E1 7 de julio el Dr. Simone Pollo, de la Facoltà di Filosofia-Università de La Sapienza en Roma (Italia) compartió su ponencia, titulada Un animalismo democrático, explicando que las creencias animalistas pueden estar enraizadas en diferentes teorías e ideas filosóficas, pero en general el animalismo es uno de los grandes movimientos de opinión de la era moderna y contemporánea, y tiene sus raíces en algunos de los principios e ideas de las sociedades liberales y democráticas contemporáneas, por lo que puede entenderse como parte de la forma de vida democrática.

La sesión en directo del 8 de julio contó con un extenso y prestigioso plantel de siete conferenciantes. En primer lugar, Reineke Hameleers, CEO del Eurogroup for Animals, expuso la necesaria protección de los animales y su papel central en la recuperación del Covid-19 de la UE. Junto con sus 70 organizaciones miembros, el Eurogrupo para los Animales lanzó la campaña "Detengamos las pandemias, actuemos ahora" para concienciar sobre los riesgos de las enfermedades zoonóticas y vincularla a la agenda de la UE. Aunque todavía queda un largo camino por recorrer, el nuevo Acuerdo Verde de la UE y el compromiso de la Comisión Europea con una recuperación verde, guardan muchas promesas de transición hacia la elaboración de políticas ecocéntricas.

A continuación, el Dr. Peter Stevenson, también de Compassion in World Farming, donde actúa como 
Asesor jefe de política, se centró en el análisis de la estrategia De la Granja a la Mesa de la Comisión y la posibilidad de transformarla en una reforma de gran alcance de la agricultura de la Unión Europea.

El punto de partida consiste en la autocrítica y el reconocimiento de que en la UE gran parte del sector ganadero de la UE es industrial con bajos estándares de bienestar. Las condiciones estresantes y hacinadas de la producción ganadera industrial contribuyen a la aparición, propagación y amplificación de patógenos, algunos de los cuales son zoonóticos.

Además, el uso recurrente de antimicrobianos para prevenir las enfermedades bacterianas que son inevitables cuando los animales se mantienen en malas condiciones, conduce a la aparición de resistencia a los antimicrobianos en animales que a su vez puede transferirse a las personas, disminuyendo la eficacia de los antimicrobianos que son tan importantes en la medicina humana.

Para el Dr. Stevenson, es necesario transformar el papel de los animales y pasar a la agricultura regenerativa, como la agroecología, que puede minimizar el uso de pesticidas y fertilizantes al mismo tiempo que mejora la productividad apoyando y aprovechando los procesos naturales.

Acto seguido asistimos a la exposición de la Dra. Maureen O'Sullivan, de la Universidad Nacional de Irlanda, que examinó casos judiciales incoherentes sobre los derechos de los vegetarianos y veganos en Irlanda, el Reino Unido y el Tribunal Europeo de Derechos Humanos, en los que los tribunales inferiores a veces ignoran las interpretaciones generales de los tribunales superiores. También llamó la atención sobre la proliferación de terminología confusa que surge de la jurisprudencia.

Por su parte, la Dra. María de las Victorias González Silvano, de la Universidad de Buenos Aires (Argentina) abordó el tema de la demonización de los animales en la época del coronavirus, de cómo el ser humano culpa a los animales - murciélago, pangolín, etc. - del mal pandémico.

La Dra. Verónica Aillón, presidenta de Victoria Animal (Ecuador), nos habló, a través de la leyenda de Osiris, de los cambios necesarios en la cultura humana para mantener la vida, (re)construyendo el respeto hacia los animales. En su disertación, denunció la situación crítica que atraviesa nuestro planeta, debido a la crisis sanitaria rebasa cualquier parámetro, haciendo hincapié en el hecho de que el ser humano, como eje rector de la naturaleza, ha usado y abusado de los animales a su antojo, sin olvidar que la crisis se causa por la ingesta de animales.

El Dr. Jordi Serratosa, en su calidad de director del debate, cedió la palabra a Juan Pablo Meneses, Periodista y Escritor y Director de la Universidad Portátil de Chile. Su intervención abordó el libro La vida de una vaca. En la obra, el lector se enfrenta a un autor que compra una vaca en Argentina, le pone nombre, cuenta su vida en medios de comunicación de distintos países, y la sigue por varios años.

Por último, la Dra. Brenda Yesenia Olalde Vázquez, desde México, intervino en el debate con un speech titulado Animales no humanos. Una oportunidad para la abolición de la esclavitud especista, en la que destacó que la actual emergencia sanitaria, obliga a cuestionar sobre los efectos de la "normalidad" antropocéntrica, que nos ha llevado a esta crisis y es que, acciones humanas tan comunes, como tomar un vaso de leche o consumir una porción de carne, impacta negativamente en el entorno natural.

Una nueva sesión en vivo, el 13 de julio de 2020, comenzó con la intervención de la Dra. Charlotte E. Blattner, de la Universidad de Berna, con una exposición titulada De la Zoonosis a la Zoópolis, en la que argumenta que la crisis del Corona es una llamada de atención para reconsiderar, reenmarcar y reorientar las relaciones hombre-animal. También abordó los vínculos existentes entre las pandemias y la agricultura industrial, las similitudes estructurales entre la opresión humana y animal, y las oportunidades de considerar a los animales en la determinación del bien público, y de trabajar hacia una sociedad inter-especies compartida.

Martina Pluda, del ICALP - UAB, expuso de qué forma el comercio de fauna silvestre, el confinamiento intensivo de animales de granja y la cría de animales de peletería representan una seria amenaza para la salud pública. El 75\% de las enfermedades infecciosas emergentes en los seres humanos son zoonóticas, originadas en los animales. En conjunto, las zoonosis son responsables por miles de millones de enfermedades y millones de muertes en todo el mundo. Para prevenir futuras pandemias, es imprescindible abordar tres cuestiones clave de protección animal: el comercio de animales salvajes vivos; el confinamiento intensivo de animales de granja; la cría y el comercio de animales de peletería.

En tercer lugar, Melanie Montenegro-Pérez, bióloga especializada en Conservación de la Biodiversidad y Derecho Animal, se centró en cómo el Coronavirus no es sino otro aviso sobre el mal trato del Homo sapiens hacia sus compañeros de vida. El Homo sapiens es una especie entre los millones que constituyen la biodiversidad mundial. Sin embargo, el trato hacia sus compañeros de vida, el resto de los seres vivos deja mucho que desear, habiendo derivado en la situación de crisis planetaria actual.

La dirección del debate dio la palabra al Dr. Joan Lluís Pérez Francesch, de la Facultad de Derecho de la UAB, quien habló de como la crisis del coronavirus nos ha puesto de manifiesto la fragilidad humana en términos integrales, que ha impactado sobre un tejido laboral y social precarizado. Por ello hay que centrar el foco de la reflexión y de las propuestas político-sociales en el desarrollo de la ética del cuidado, comunitaria 
e institucionalmente considerada, de manera que se desarrolle una nueva centralidad del respeto por el medio ambiente, la sentiencia animal, la protección del interés superior del menor o la reconfiguración del Estado del Bienestar a partir del "tercer sector" y de los derechos prestacionales. La incertidumbre actual debe llevarnos a una lucha por la justicia y la democracia en la que los elementos citados son imprescindibles.

Acto seguido Randall S. Abate, de la Monmouth University (EE.UU), hizo hincapié en cómo el coronavirus puede mejorar el progreso en la protección animal en los EE.UU a través de dos medios indirectos: (1) promover la conciencia de la urgencia y la viabilidad de los esfuerzos mejorados de mitigación del cambio climático y (2) acelerar la transición desde la agricultura animal industrial hacia un sistema de alimentación a base de plantas.

La Dra. Rosa María de la Torre Torres, de la Universidad Michoacana de San Nicolás de Hidalgo (México), comentó la tesis 163/2018 de la Suprema Corte de Justicia de la Nación, en la que aprobó, por unanimidad, el reconocimiento del bienestar animal como un principio implícito de la Constitución mexicana Dentro de los argumentos de la Corte, destaca el reconocimiento del bienestar animal como un principio constitucional implícito que obliga a que se establezcan las medidas conducentes a limitar y erradicar todas aquellas prácticas culturales contrarias al mismo, aun cuando éstas gocen de importante arraigo cultural.

A continuación, el Dr. Luciano Rocha Santana, (miembro del ICALP y profesor de la Universidade de Salvador de Bahía en Brasil) expuso la ponencia elaborada junto a Thiago Pires Oliveira (de la Universidade de Sao Paulo, en Brasil, quien también intervino en las sesiones) y titulada Fundamentos éticos de las Políticas Públicas de Guarda Responsable de Animales y la Pandemia de COVID-19, en la que destaca que las políticas públicas dirigidas a la salud animal no deben consistir solo en meras obligaciones morales, sino en acciones institucionales preventivas que buscan abordar la raíz de los problemas de salud pública causados por algunos tipos de zoonosis. Las zoonosis son el resultado de un desequilibrio en las relaciones humanas con el mundo natural y superar este desequilibrio requiere el establecimiento de una nueva postura ética para los seres humanos, a fin de modificar no solo su comportamiento para con los animales, sino también revisar su conducta para con la naturaleza como un todo.

Ignacia Uribe, exdirectora de Cosmopolitan en Chile, y Cristian Apiolaza, abogado y profesor hablaron sobre Covid-19, moda y políticas públicas: los peligros del confinamiento de animales salvajes en la industria peletera, denunciando que, en el contexto actual de la crisis sanitaria mundial que ha generado la pandemia del Coronavirus, se hace necesario poner atención sobre otras fuentes posibles de transmisión de zoonosis, como lo es la industria peletera. En ella, se crían de forma intensiva animales salvajes -como visones y zorros, entre otros- con el objetivo de utilizar su piel para confeccionar prendas de alta costura, aun cotizadas en algunos centros de la moda internacional.

La intervención del Dr. Juan Ignacio Serra, de la Universidad de Buenos Aires (Argentina) se centró en la importancia de analizar la situación y posibles soluciones en la que viven los más indefensos y perjudicados por esta pandemia: los animales no humanos.

A continuación, el Dr. Josep Cañabate Pérez, de la Facultad de Derecho de la UAB, defendió una ponencia titulada Seguridad sanitaria, derechos de los animales y privacidad: un frágil equilibrio en tiempos de pandemia. En primer lugar, expuso la necesidad de reflexionar acerca del impacto sobre la privacidad de las personas el tratamiento de datos de sus animales. La segunda cuestión que trató consiste en si los animales por sí mismos tienen derecho a la privacidad y a la protección de datos personales.

La propia moderadora, la Dra. Elisabeth Montero, que desempeñó su función de forma impecable, intervino para presentar su propia ponencia, Propuesta de protocolo para México para animales ante pandemias, exponiendo un protocolo ideal para la República Mexicana que contenga las normas mínimas que deberían de acotar las autoridades y los particulares respecto a los animales de compañía, animales en zoológicos, en acuarios, en la producción, y en la experimentación o investigación ante cualquier Pandemia, como en el caso que estamos viviendo del COVID19.

Al día siguiente, y desde Estados Unidos, Carly Elisabeth Souther, compartió su conferencia Promoviendo protecciones pandémicas: Oportunidades para el avance y la defensa de los animales en medio de los desafios del COVID-19, en la que destacó que el bienestar de los animales no humanos en la pandemia ha sido (con razón) eclipsado por el grave sufrimiento humano. También exploró la interacción entre la tecnología alimentaria, el comercio de vida silvestre, el campo emergente del derecho animal global y establecidos principios del derecho internacional, como los derechos humanos y la soberanía del Estado.

La sesión de clausura contó en primer lugar con la presencia del Ilmo. Sr. Sergio Antonio García Torres, Director General de Derechos de los Animales, quien repasó las políticas existentes en materia de protección animal y expuso las líneas de trabajo del Gobierno actual en relación con los animales, en concreto la elaboración de una nueva ley de protección animal, que regule, entre otras materias, el abandono de animales de compañía, reformando su registro y trazabilidad. Anunció también la reforma del Código Penal en el sentido de ampliar la protección animal, así como la reforma del Código Civil en el sentido de reconocer la 
sentiencia animal.

Tras la esperanzadora intervención del Sr. García Torres, el Dr. Kyle Harper, Profesor de Clásicas y Letras y Vicepresidente Senior y Preboste de la Universidad de Oklahoma, ofreció una interesante ponencia titulada De la antigua Roma a Wuhan: La ecología de la enfermedad surge en perspectiva histórica. Basándose tanto en fuentes históricas escritas como en nuevas percepciones de los datos genéticos, esta charla explorará lo que una perspectiva histórica puede decirnos sobre la importancia de las relaciones ecológicas con los animales salvajes, domésticos y comensales para la salud humana.

En resumen, el webinar supuso una muestra increíble de pluralidad y conocimiento, presentando un excelente y plural plantel de ponentes, superando con creces las dificultades que plantea la situación actual a la celebración de cualquier acto académico. De una forma que sorprende, si no fuera porque somos conocedores del enorme esfuerzo y trabajo que lo sustenta, el seminario consiguió superar las desventajas nacidas de la actual pandemia y construir un lugar virtual en el que un elenco extraordinario de organizadores, ponentes, moderadores y asistentes pudieran poner en común las inquietudes del Derecho animal en el estado actual ocasionado por la incidencia de la pandemia originada por el COVID-19. 